\title{
PELATIHAN BUDIDAYA HIDROPONIK SAYUR DAUN: PEMBERDAYAAN MASYARAKAT PANYIRAPAN BANTEN, INDONESIA DI MASA PANDEMI COVID-19
}

\author{
Irva Faoji Anwar ${ }^{1}$, Lia Junita Harahap ${ }^{2 *}$ \\ ${ }^{1}$ Pendidikan Biologi, Universitas Negeri Jakarta \\ ${ }^{2}$ Tadris Biologi, Institut Agama Islam Negeri Padangsidimpuan \\ *liajunita52@gmail.com
}

\begin{abstract}
Panyirapan is a village whose community work is dominated by farmers. People are still farming conventionally and do not know the techniques of farming with a hydroponic system. The hydroponic training conducted by BLK Lembang aims to educate the people of Panyirapan village to switch to hydroponic farming that is more environmentally friendly. The training method consisted of providing theory and practice by BLK representative instructors. The training participants were 16 people who were heterogeneously selected and grouped into 4 groups. The vegetable crops grown are pakcoy, red lettuce, green lettuce, spinach and kale. The results of the training show that the training participants have competence in the field of hydroponics which is attached to the graduation certificate which is distributed to the trainees at the end of the series of training activities. The training activities provide knowledge to the community, especially the training participants on how to grow modern crops (hydroponics), being able to motivate themselves to become entrepreneurs in the field of hydroponic agriculture by forming a hydroponic farmer group, namely the fragrant blooming hydroponic vegetable community. The community actively sells their harvests in the form of pakcoy, spinach, lettuce and kale to the Panyirapan community.
\end{abstract}

Keywords: Hydroponic Training, Community Empowerment, NFT System, Wick System

\begin{abstract}
Abstrak
Panyirapan merupakan desa yang pekerjaan masyarakatnya didominasi oleh petani. Masyarakat masih bertani secara konvensional dan kurang mengetahui teknik bercocok tanam dengan sistem hidroponik. Penelitian tindakan dilalukan melalui Pelatihan hidroponik yang dilakukan oleh BLK Lembang bertujuan untuk mengedukasi masyarakat desa Panyirapan agar beralih ke pertanian hidroponik yang lebih ramah lingkungan. Metode pelatihan terdiri dari pemberian teori dan praktik oleh instruktur perwakilan BLK. Peserta pelatihan sebanyak 16 orang yang dipilih secara heterogen dan dikelompokan menjadi 4 kelompok. Komoditas tanaman sayuran yang ditanam yaitu pakcoy, selada merah, selada hijau, bayam dan kangkung. Hasil pelatihan menunjukkan bahwa para peserta pelatihan telah memiliki kompetensi di bidang hidroponik yang terlampir pada sertifikat lulus yang dibagikan kepada para peserta pelatihan di akhir rangkaian kegiatan pelatihan. Kegiatan pelatihan memberikan pengetahuan kepada masyarakat khususnya para peserta pelatihan mengenai cara bercocok tanam modern (hidroponik), mampu motivasi untuk berwirausaha di bidang pertanian hidroponik dengan terbentuknya kelompok tani hidroponik yaitu komunitas sayuran hidroponik mekar wangi. Komunitas tersebut aktif menjual hasil panennya berupa pakcoy, bayam, selada dan kangkung ke lingkungan masyarakat panyirapan.
\end{abstract}

Kata Kunci: Pelatihan Hidroponik, Pemberdayaan Masyarakat, Sistem NFT, Sistem Wick 


\section{PENDAHULUAN}

Masa pandemi Covid-19 memaksa masyarakat membatasi aktivitas di luar rumah sesuai anjuran pemerintah yaitu social distancing. Pekerjaan masyarakat terbengkalai sehingga penghasilan mengalami penurunan. Tidak banyak yang bisa dikerjakan, aktivitas pun menjadi tidak produktif. Sedikit berbeda dengan masyarakat di Desa Panyirapan yang berada pada zona hijau yang berarti aman dari Covid-19 karena tidak ada ditemukan korban Covid-19 sampai bulan kesembilan masa pandemi sehingga sangat minim dalam penyebaran virus corona. Meskipun masih bisa beraktivitas seperti biasa tetapi beberapa diantaranya kehilangan pekerjaan yaitu masyarakat yang pekerjaannya sebagai pedagang barang-barang yang sifatnya tersier.

Berdasarkan profil desa Panyirapan, potensi utama desa ini terdapat pada sektor pertanian. Sebagian besar lahan digunakan sebagai lahan pertanian yaitu sebesar 136, $94 \mathrm{Ha}$ dengan persentase $77,25 \%$ dari luas wilayah desa Panyirapan. Jumlah penduduk desa yang bekerja pada sektor pertanian sebanyak 635 jiwa. Lokasi dan suasana desa Panyirapan yang sejuk sangat mendukung dalam bertani. Tetapi sebagian masyarakat tidak memiliki lahan untuk bertani. Meningkatnya populasi manusia atau pertumbuhan penduduk menjadi salah satu penyebab tergantinya lahan bertani menjadi permukiman warga. Hal ini sejalan dengan (Asmana et al., 2017; Harahap et al., 2019) lahan pertanian semakin menyempit karena lahan tersebut dialihfungsikan menjadi daerah perindustrian dan tempat tinggal masyarakat. Di sisi lain, permintaan pasar akan hasil pertanian seperti sayuran semakin tinggi seiring peningkatan populasi penduduk (Vidianto et al., 2012; Aksa et al., 2016). Hal ini tidak diimbangi dengan penambahan luas lahan untuk menanam sayur, hasil panen juga tidak menentu karena hama dan cuaca yang tidak menentu. Musim kemarau, kenaikan suhu, pengelolaan sumber daya air yang tidak tepat, dan penurunan permukaan air tanah merupakan ancaman perubahan iklim pada tanaman konvensional. Oleh karena itu budidaya dengan sistem hidroponik dianggap tepat untuk memanfaatkan lahan yang ada dengan bijak.

Untuk memanfaatkan situasi dan kondisi pandemi agar tetap produktif maka sangat tepat diadakan pemberdayaan masyarakat melalui pelatihan hidroponik di zona hijau. Hidroponik adalah salah satu teknik penumbuhan tanaman tanpa melibatkan tanah sebagai media tanamnya, tetapi air dan nutrisi yang merupakan media pertumbuhan dan perkembangannya (Savvas, 2004; Palande et al., 2018). Penumbuhan tanaman dengan sistem hidroponik dapat ditempatkan di dalam atau luar ruangan, dapat diimplementasikan sepanjang tahun atau tidak tergantung pada musim (Wibowo \& Asriyanti, 2013; Maulido et al., 2016) bebas pestisida, kondisi lingkungan seperti intensitas cahaya, suhu, dan 


\section{JURNAL PEMBERDAYAAN MASYARAKAT $\mid 138$ \\ Volume 9 No. 2 Tahun 2021 ISSN: 2355-8679}

kelembaban dapat diatur sehingga serangan hama penyakit relatif kecil (Domingues et al., 2012; Majid et al., 2020) yang pada akhirnya menghasilkan sayur organik yang lebih fresh dan sehat. Sayuran fresh tanpa banyaknya perlakuan atau tanpa penggunaaan pestisida sangat dibutuhkan masyarakat di era pandemi seiring dengan meningkatnya pengetahuan masyarakat akan bahaya mengkonsumsi sayuran yang sudah terkontaminasi pestisida selama masa pertumbuhan mulai dari benih sampai pada masa panen.

Manfaat lain penggunaan hidroponik adalah mampu mengurangi biaya pengadaan air dan toksisitas atau dampak negatif terhadap lingkungan seperti pencemaran tanah dan air (Sharma et al., 2019). Nutrient Film Technique (NFT) dan Wick merupakan jenis sistem budidaya hidroponik. Hidroponik NFT dilakukan dengan teknik pemberian larutan nutrisi sesuai kebutuhan tanaman melalui aliran air dengan arus pelan dan dangkal sehingga bagian atas akar mendapatkan oksigen yang cukup serta tercipta lapisan tipis (film) larutan mineral dan nutrisi di sekitar akar (Pancawati \& Yulianto, 2016; Helmi et al., 2016). Teknis hidroponik NFT dapat disusun secara bertingkat dengan bahan tiang penyangga sederhana dan secara ekonomis dapat menghasilkan produksi yang lebih tinggi (Frasetya et al., 2018). Sistem Wick adalah sistem hidroponik yang efektif untuk skala rumah tangga, khususnya pada tanaman sayuran. Sistem wick memiliki nilai estetika yang tinggi dan mudah dipantau. Oleh karena itu, untuk mendapatkan skill, usaha baru atau lapangan kerja baru perlu adanya pelatihan hidroponik NFT untuk memberdayaan masyarakat Panyirapan Banten, Indonesia.

Berdasarkan analisis situasi yang telah diuraikan, diantaranya masyarakat yang didominasi oleh petani konvensional yang bergantung pada situasi musim, maka diperlukan pemberdayaan masyarakat di bidang hidroponik sebagai salah satu cara mengatasi masalah di masyarakat dalam peningkatan sumber daya manusia di bidang pertanian. Diharapkan kegiatan ini dapat meningkatkan wawasan, kreatifitas, dan peningkatan kesejahteraan ekonomi masyarakat.

\section{METODE PENELITIAN}

Penelitian ini merupakan penelitian tindakan dengan pendekatan kualitatif deskriptif. Pendekatan kualitatif deskriptif digunakan untuk mengeksplor fenomena-fenomena yang tidak dapat dikuantifikasikan atau yang bersifat deskriptif seperti proses suatu langkah kerja, pengertian- konsep-konsep yang beragam, formula resep, karakteristik barang dan jasa, tata cara suatu budaya, model artefak dan lain sebagainya yang kemudian dijabarkan sebagaimana 
adanya atau sesuai dengan kondisi objek yang alamiah (Djam'an \& Aan, 2010; Sugiyono, 2018).

Sasaran pelatihan hidroponik yaitu kelompok tani, ibu rumah tangga dan para pemudapemudi yang berada di desa Panyirapan, Kecamatan Baros, Kabupaten Serang, Provinsi Banten. Kegiatan pelatihan diadakan dan dibimbing oleh Balai Latihan Kerja (BLK) Lembang. Waktu pelaksanaan dimulai dari tanggal 27 Oktober 2020 sampai 12 November 2020. Prosedur pelaksanaan terdiri dari beberapa rangkaian kegiatan pada Gambar 1.

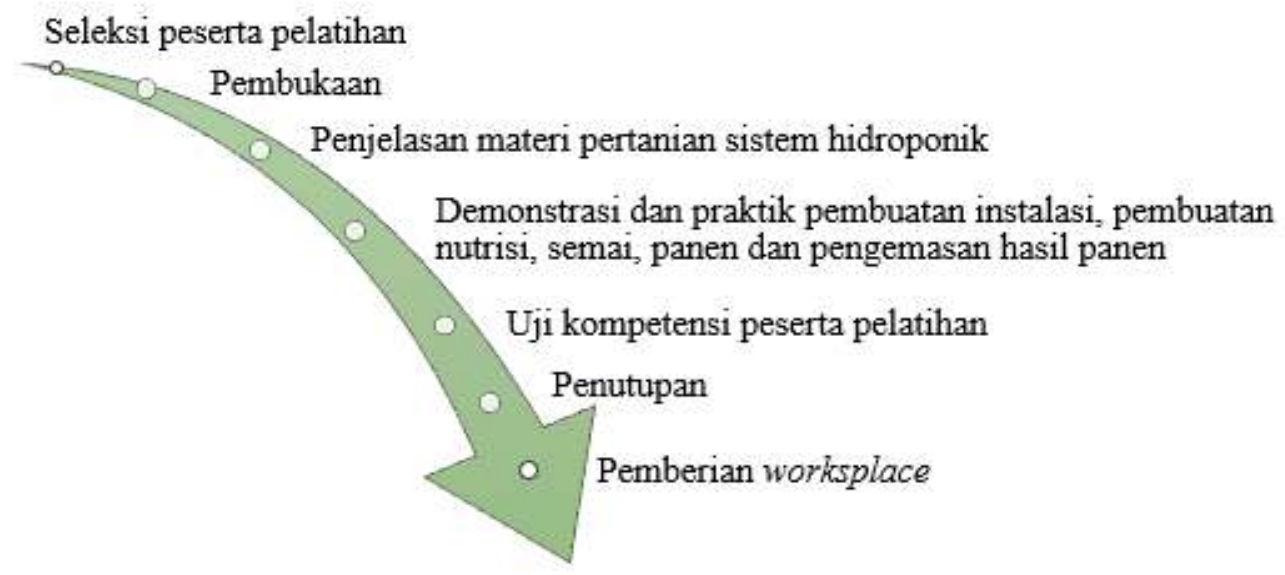

Gambar 1. Prosedur Pelaksanaan Pelatihan Hidroponik

Kegiatan pelatihan diawali dengan kegiatan penyeleksian peserta pelatihan yang terdiri dari beberapa tes yaitu tes administrasi, tes tertulis, dan wawancara. Tes administrasi merupakan tes yang mendeskripsikan kelengkapan berkas peserta, seperti KTP, kevalidan Nomor Induk Kependudukan, Kartu Keluarga, pas foto dan email. Tes tertulis merupakan tes yang digunakan untuk mengetahui seberapa jauh wawasan peserta tentang dunia pertanian khususnya hidroponik. Selanjutnya tes wawancara merupakan tes untuk mengetahui seberapa siap, serius dan komitmennya peserta untuk mengikuti pelatihan kompetensi hidroponik.

Tahapan tahapan tersebut menyeleksi peserta pelatihan yang awalnya peserta yang mendaftar sekitar 20 orang tersaring menjadi 16 peserta. Ketidakberhasilan peserta dalam melewati tahapan seleksi tersebut karena masalah kelengkapan data administrasi dan kesiapan peserta dalam mengikuti pelatihan dari awal hingga akhir. Peserta wajib mengikuti aturan pelatihan dari awal pembukaan hingga penutupan. Metode pengumpulan data yang digunakan adalah observasi, wawancara, dan focus group discussion (FGD). 
Selanjutnya data yang berhasil dikumpulkan, dianalisis untuk dapat memahami dan mendapatkan kesimpulan. Peserta yang telah lulus akan diberikan sebuah sertifikat kelulusan dengan kompetensi yaitu mampu: 1) menerapkan ketentuan keselamatan, kesehatan kerja dan lingkungan di tempat kerja, 2) menanam bahan tanam, 3) mengembangkan kerjasama tim, 4) menyediakan prasarana pesemaian tanaman, 5) mendesain sistem irigasi ,6) memasang sistem hidroponik, 7) memonitor sistem hidroponik, 8) memelihara sistem hidroponik, 9) memanen hasil tanaman 10) melaksanakan prinsip kewirausahaan secara optimal. Dari pelatihan ini, kelompok tani hidroponik mekar wangi yang telah terbentuk akan terus dikembangkan dan mampu menghasilkan sayur hidroponik untuk dikonsumsi keluarga mekar wangi dan untuk dijadikan sebagai lahan bisnis di bidang ekonomi pertanian yaitu dengan menjual sayur ke pasar atau super market.

\section{HASIL DAN PEMBAHASAN}

Kegiatan pelatihan bercocok tanam secara hidroponik dibuka oleh kepala BLK Lembang yang dihadiri oleh beberapa perwakilan petugas BLK Lembang, aparatur desa, warga masyarakat Panyirapan dan peserta pelatihan (Gambar 2).

1. Pemberian Teori Dasar Hidroponik

Proses penyampaian materi dilakukan dengan metode presentasi, diskusi kelompok dan tanya jawab. Peserta pelatihan yang berjumlah 16 orang dikelompokan menjadi 4 kelompok yang heterogen.

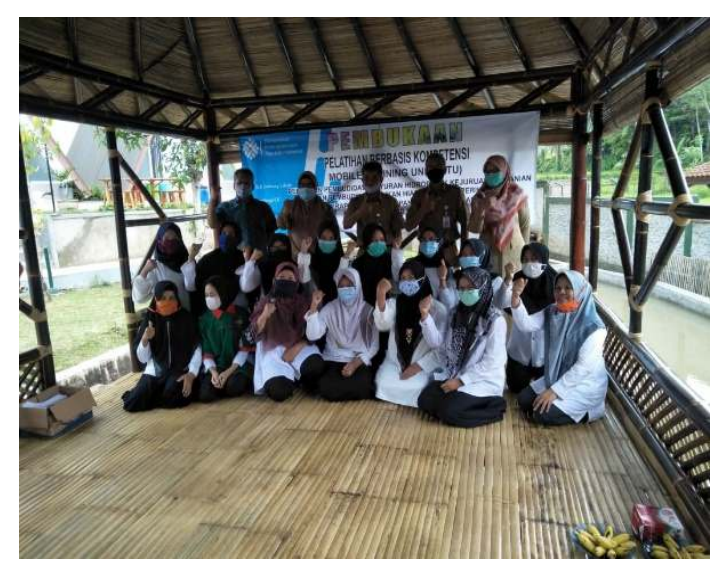

Gambar 2. Pembukaan

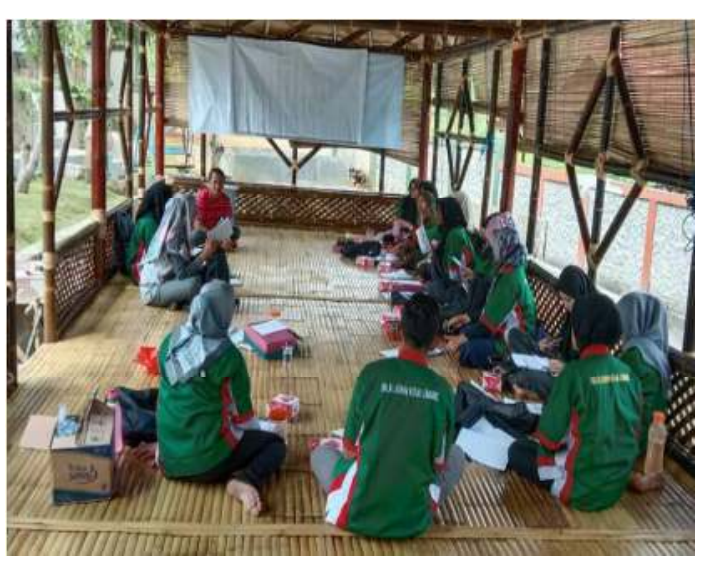

Gambar 3. Penjelasan Materi Hidroponik 
2. Praktik Membuat Model Instalasi Hidroponik.

Pada proses pelatihan peserta dikenalkan dengan 6 jenis sistem hidroponik yaitu, sistem wick/sumbu, sistem rakit apung, sistem pasang surut (Ebb and Flow), sistem NFT, sistem DFT, sistem drif dan sistem aeroponik. Dari ke 6 sistem hidroponik, yang dipraktikan hanya 2 sistem yaitu sistem wick dan sistem NFT.

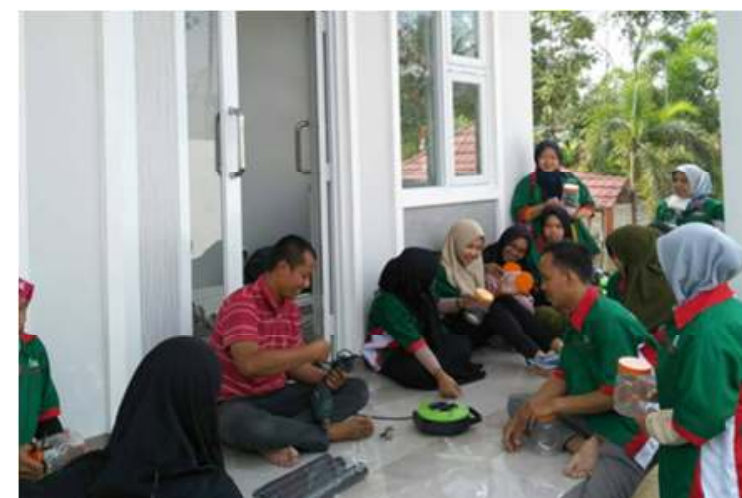

Gambar 4. Pembuatan Sistem Wick

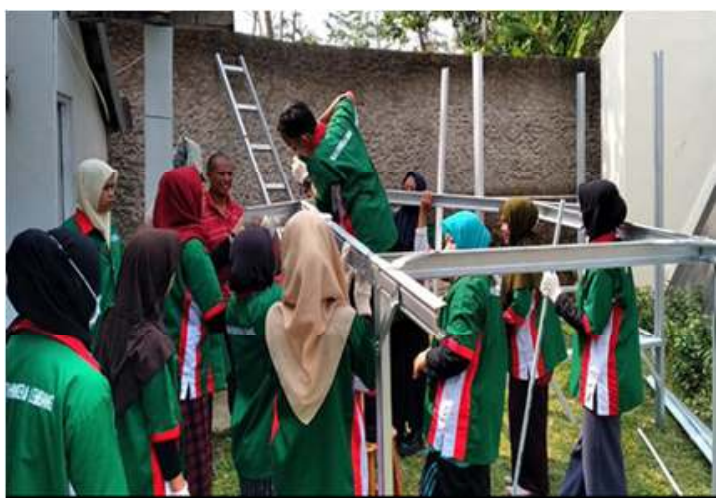

Gambar 5. Pembuatan Sistem NFT

3. Praktik Membuat Stock Larutan Nutrisi AB Mix.

Nutrisi hidroponik merupakan unsur makro dan mikro yang diperlukan tanaman untuk bisa tumbuh dan berproduksi optimal (Jerusha et al., 2021). Berikut praktik proses pembuatan stock larutan nutrisi AB Mix (Gambar 7).

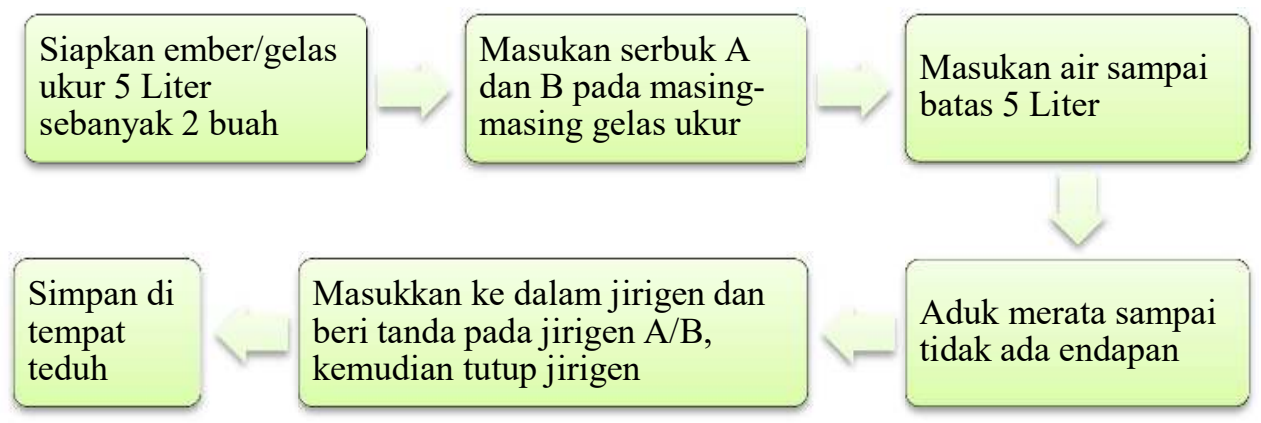

Gambar 6. Cara Membuat Stok AB Mix
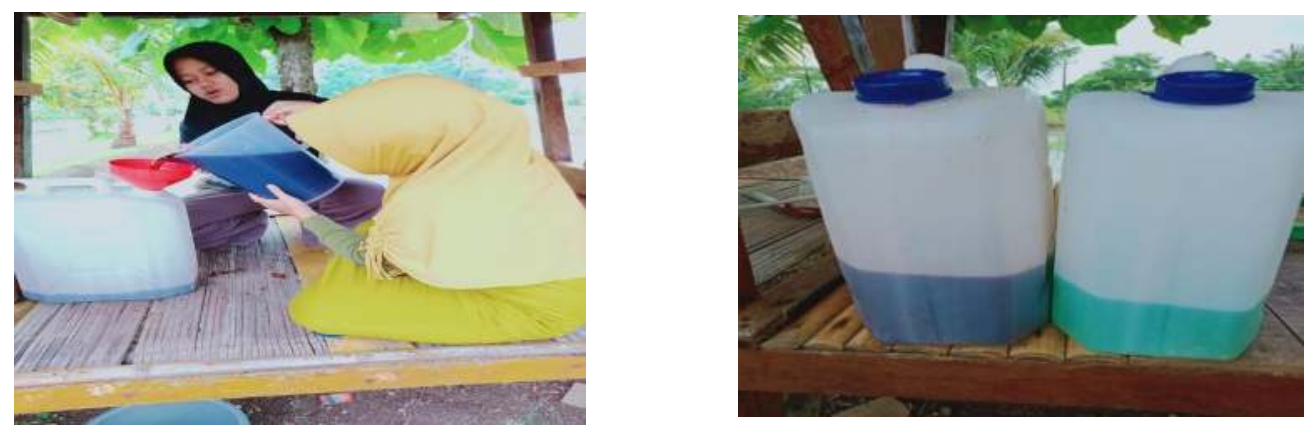

Gambar 7. Praktik Membuat Larutan Stock AB Mix

Irva Faoji Anwar, Lia Junita Harahap | Pelatihan Budidaya Hidroponik Sayur Daun: Pemberdayaan Masyarakat Panyirapan Banten, Indonesia di Masa Pandemi Covid-19 
4. Praktik Menyemai dan Pindah Tanam Benih

Peserta pelatihan diberikan keterampilan menyemai dengan menggunakan 2 media yaitu rockwul dan sekam bakar.
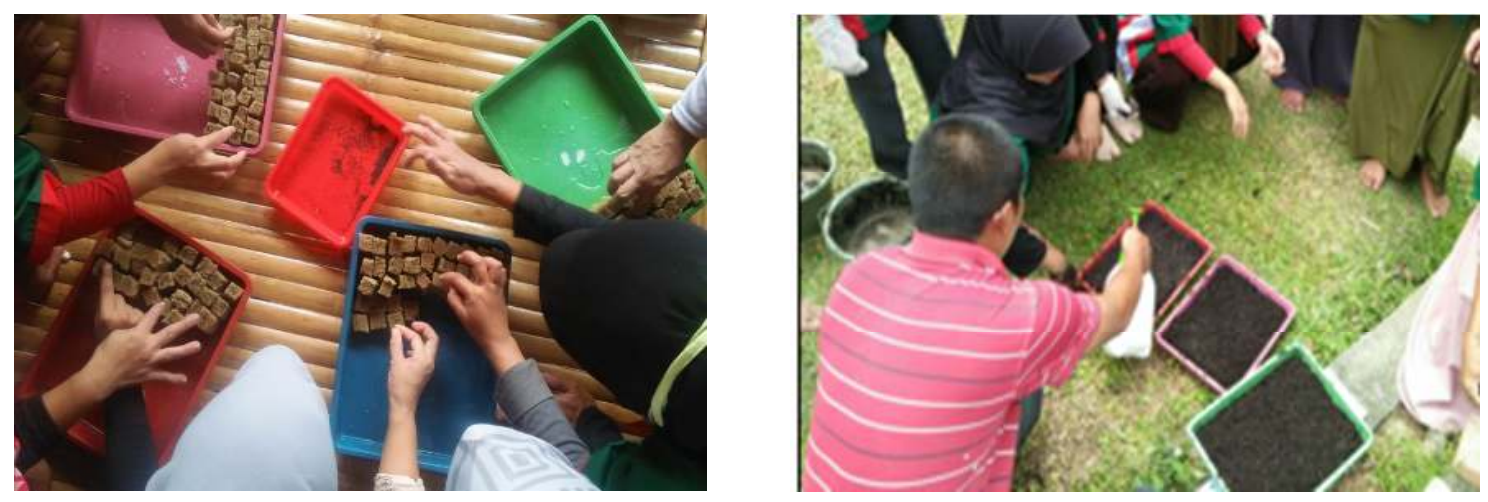

Gambar 8. Menyemai dengan Rockwul dan Sekam Bakar

Hasil semai pada sekam bakar diperlukan proses pemindahan ke media rockwul sebelum dipindahkan ke meja semai.
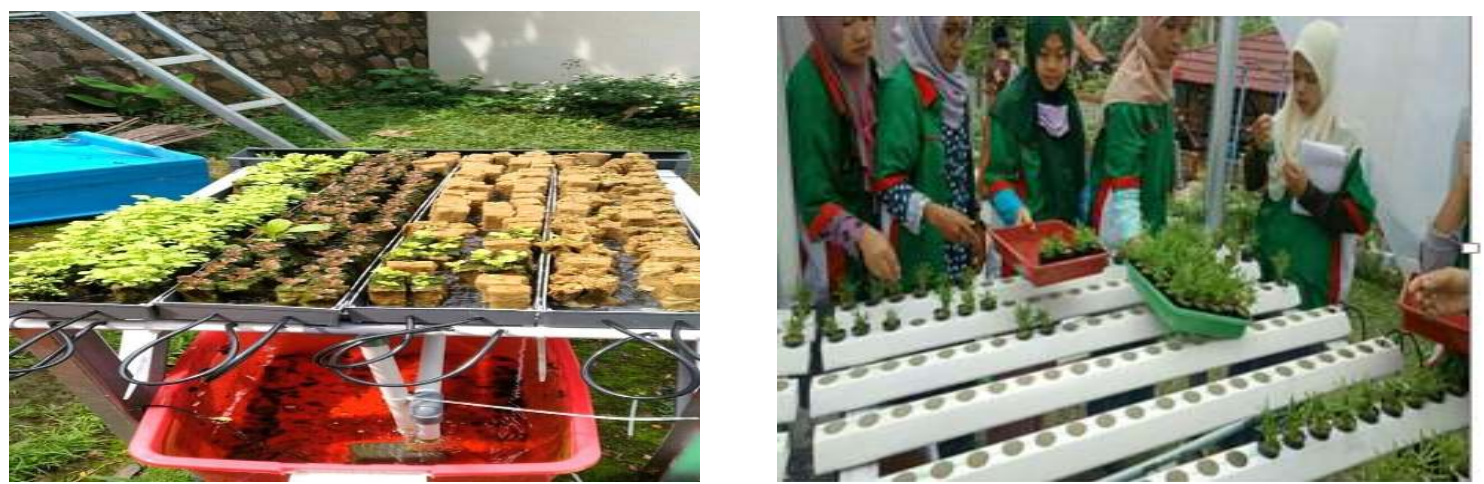

Gambar 9. Bibit pada Meja Semai Gambar Gambar 10. Pindah Tanam ke Meja Peremajaan

5. Praktek Standar Oprasional Perawatan Kebun Hidroponik

Pemeliharaan tanaman hidroponik yang sesuai dengan standar oprasional terdiri dari pengecekan instalasi, pengecekan nutrisi dan pengecekan tanaman (Tabel 1 dan Gambar 11). Hal ini sejalan (Sunardi et al., 2013) dengan pengelolaan tanaman yang baik meliputi kesesuaian komoditas yang diusahakan, kesesuaian media tumbuh, kesesuaian larutan nutrisi, dan teknik pemeliharaan. 
Tabel 1. Standar Operasional Pengecekan Tanaman Hidroponik.

\begin{tabular}{|l|l|c|}
\hline \multicolumn{3}{|c|}{ Standar Operasional } \\
\hline Pengecekan Instalasi & Pengecekan Nutrisi & Pengecekan Tanaman \\
\hline$\checkmark$ Cek sambungan tiap & $\checkmark$ Pengecekan larutan & $\checkmark$ Amati satu persatu tanaman \\
guly, inlet dan & $\checkmark$ Ppm awal & $\checkmark$ Kerdil akibat benih jelek \\
outlet & $\checkmark$ Ppm air baku & $\checkmark$ Busuk akar, batang, daun \\
$\checkmark$ Cek selang HDPE & $\checkmark$ Ppm seharusnya lihat fase & $\checkmark$ Penyemprotan pestisida \\
$\checkmark$ Cek tandon mesin & $\checkmark$ Kurang nutrisi atau sudah & nabati \\
$\checkmark$ Cek & standar (jika kurang ada & $\checkmark$ Penyulaman tanaman \\
aquarium & perhitungan) & $\checkmark$ Pembuangan tunas air dan \\
& $\checkmark$ Tambahkan AB Mix & daun tua \\
& $\checkmark$ Tambah air & \\
\hline
\end{tabular}
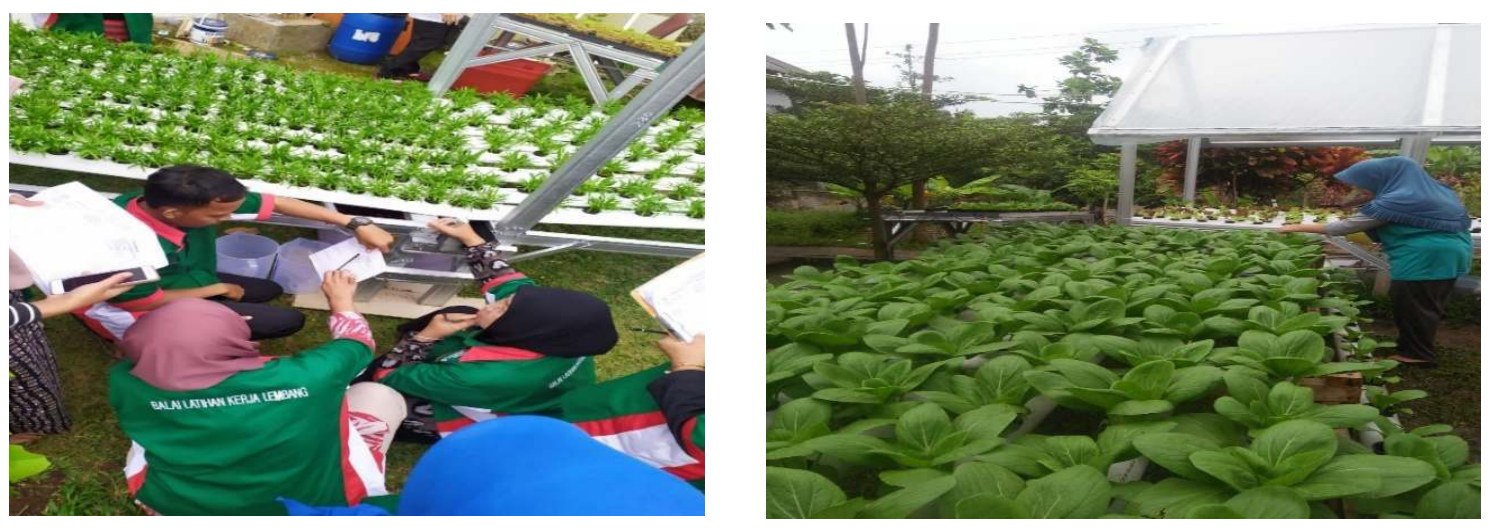

Gambar 11. Pengecekan Nutrisi dan Tanaman

\section{Panen dan Pengemasan}

Waktu yang tepat untuk panen sayuran hidroponik dapat diketahui pada saat awal semai. Setiap tanaman hidroponik memiliki masa panen atau tanggal panen yang berbedabeda. Sayuran kangkung dipanen diusia 21 hari, sedangkan pada tanaman pakcoy pada usia 35 hari. Penentuan tanggal panen dapat diketahui dari lebel tanaman yang dibuat pada awal menyemai benih (Gambar 12). 

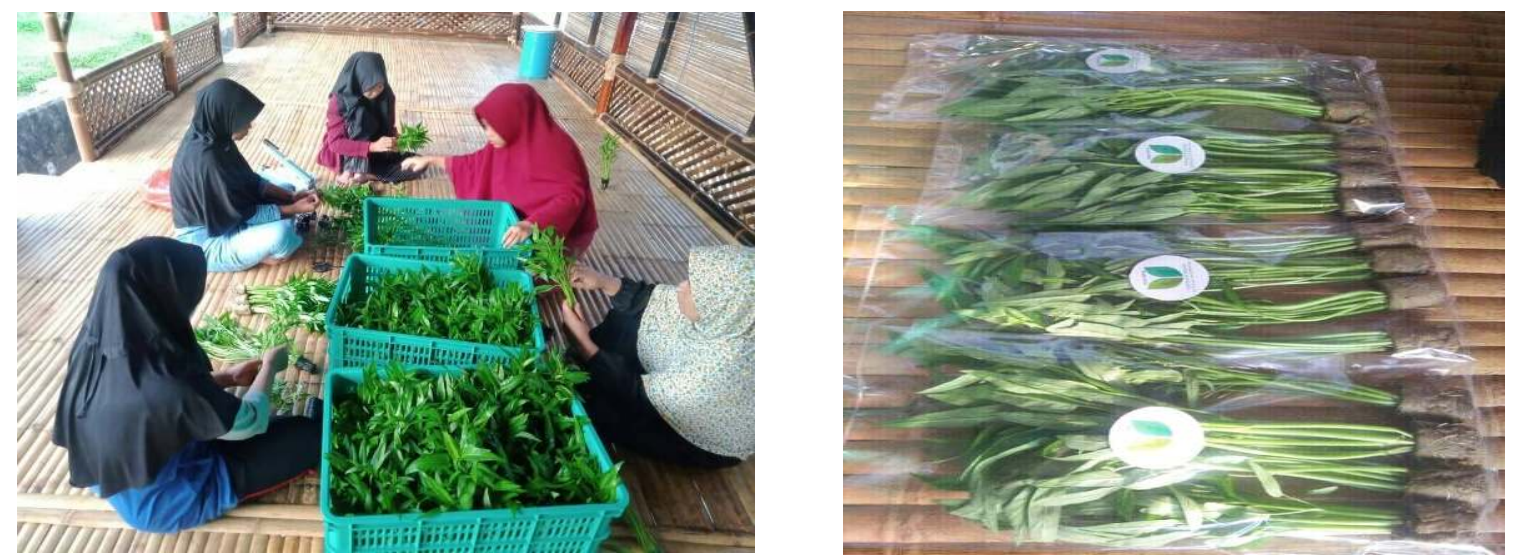

Gambar 12. Proses Panen dan Hasil Kemas Sayuran Kangkung Hidroponik

\section{Uji Kompetensi}

Pada akhir kegiatan pelatihan, para peserta pelatihan dihadapkan dengan ujian kompetensi. Ujian ini dilakukan untuk mengetahui tingkat keberhasilan pelatihan dengan melihat kompetensi peserta pelatihan. Ujian kompetensi dilakukan oleh asesor yang didatangkan langsung dari BLK Lembang.

Penutupan kegiatan dilakukan oleh perwakilan dari BLK Lembang yang dihadiri oleh aparatur desa, peserta pelatihan dan warga Panyirapan. Berakhirnya pelatihan ini disimbolisasikan dengan penyerahan sertifikat pelatihan dan pemberian worksplace (Gambar 14).
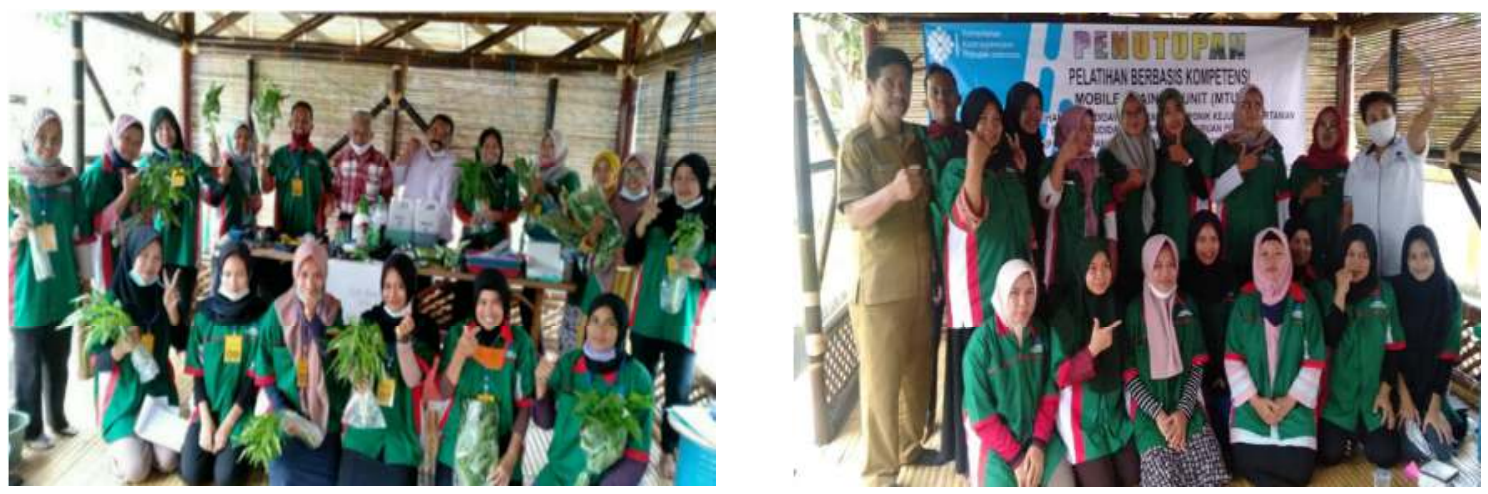

Gambar 13. Uji Kompetensi dan Penutupan Pelatihan 

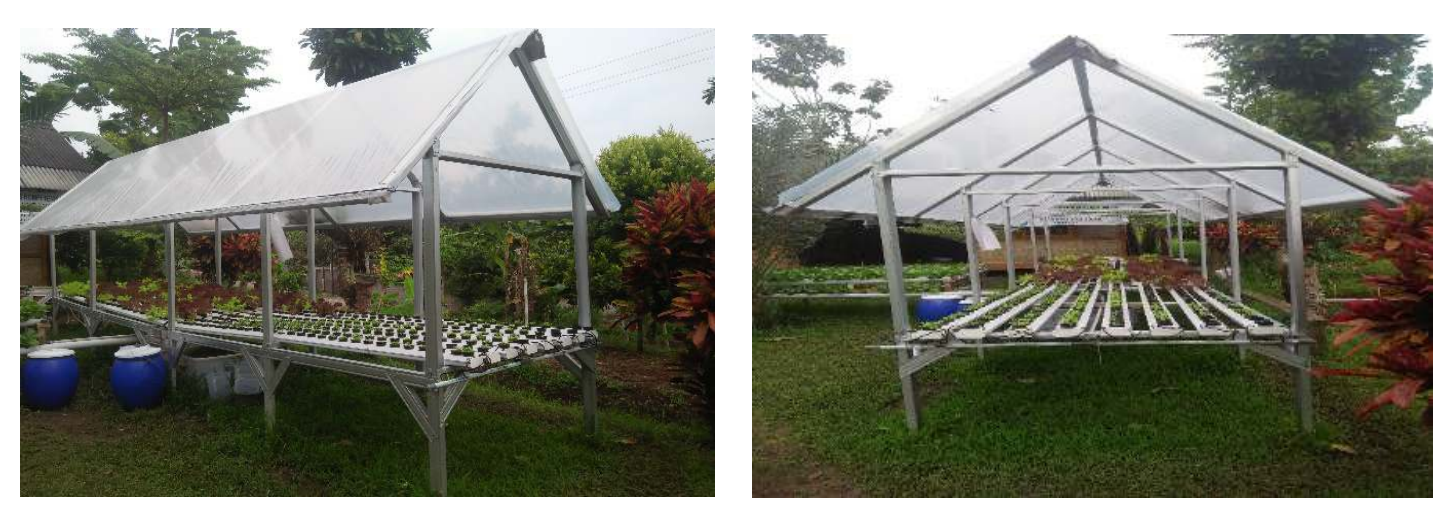

Gambar 14. Workplace yang Diberikan oleh BLK Lembang

Kegiatan pelatihan bercocok tanam hidroponik oleh BLK diharapkan mampu memberikan pengetahuan dan keterampilan kepada peserta pelatihan diataranya peserta mampu mengetahui teori dasar tentang sistem hidroponik, mampu membuat model instalasi sistem NFT dan sistem wick, mampu membuat larutan stock nutrisi AB Mix, mampu menyemai dan pindah tanam, merawat kebun hidroponik, dan terampil melakukan panen dan pengemasan sayur hidroponik. Kegiatan praktek dalam pelatihan hidroponik memiliki komposisi lebih besar presentasinya dibandingkan dengan teori. Hal ini bertujuan agar peserta tidak hanya mengetahui ilmunya tetapi mampu mengaplikasikannya setelah peserta selesai pelatihan.

Pemberian teori dasar tentang hidroponik dalam pelatihan menjadi kunci dasar dan penunjang peserta dalam melakukan kegiatan praktek. Teori dasar diberikan secara secara bertahap yang disesuaikan dengan kebutuhan praktek yang dilakukan oleh peserta pelatihan. Teori yang diberikan meliputi pengenalan definisi hidroponik, jenis-jenis sistem hidroponik, cara mencampurkan larutan $\mathrm{AB}$ Mix, cara penyemaian, pindah tanam, alat pelindung diri yang dibutuhkan untuk berkebun hidroponik, dan standar oprasional perawatan kebun hidroponik. Teori dasar bercocok tanam hidroponik disampaikan oleh instruktur BLK (Gambar 3).

Sistem wick merupakan sistem hidroponik yang sangat sederhana. Sistem ini memanfaatkan sumbu yang berupa kain flannel sebagai penghantar larutan nutrisi ke akar tanaman (Zainudin \& Abror, 2021). Sistem ini memiliki kelemahan yaitu distribusi oksigen ke tanaman sangat sedikit, karena air nutrisi dalam kondisi pasif, sehingga tempat air nutrisi yang digunakan perlu digoyang-goyangkan agar air nutrisi bergerak dan kandungan oksigen dalam nutrisi untuk tanaman tercukupi. Selain perlu adanya proses penggantian air nutrisi 
secara periodik, misalnya dalam jangka waktu dua hari sekali. Hal tersebut menyebabkan penggunaan nutrisi menjadi boros penggunaannya. Sistem wick memerlukan alat (toples sosis, netpot, bor dan holdsaw) dan bahan (larutan nutrisi, kain flannel, benih atau bibit, rockwool). Setiap peserta pelatihan diberikan tugas individu untuk mampu membuat sistem wick. Peserta pelatihan diawali dengan mengamati instruktur membuat model sistem wick dari toples, kemudian peserta pelatihan mempraktikannya secara bergantian (Gambar 4).

Sistem hidroponik NFT merupakan sistem hidroponik yang sering digunakan untuk skala usaha. Sistem hidroponik NFT yaitu sistem hidroponik yang memanfaatkan aliran nutrisi tipis dalam pemberian nutrisi, air nutrisi terus tersikulasi agar pasokan oksigen, air dan nutrisi untuk tanaman tercukupi (Wibisono \& Kristyawan, 2021). Kelemahan sistem ini yaitu air harus terus menerus mengalir, dan penularan penyakit lebih cepat dibandingkan sistem lain. Instalasi sistem NFT yang dibuat berukuran 3 x 1.5 Meter (Gambar 5). Beberapa alat bahan material yang digunakan dalam membuat kebun hidroponik dengan menggunakan instalasi sistem NFT yaitu canal c, reng, talang, paralon $1 / 2$ inci, gully, plastik UV, T dan L, selang HDPE, pompa air, drigen 5 Liter, gelas ukur plastik 5 liter, gelas ukur $500 \mathrm{ml}$, netpot, tandon, kabel dan colokan, holdsaw, bor, gurinda, rockwool, AB Mix, dan benih.

Kelemahan sistem NFT yaitu adanya ketergantungan pada daya pompa air yang harus menyala terus setiap waktu (Suryaningprang et al., 2021). Pada saat terjadi mati lampu tanaman pada sistem NFT menjadi layu. Hal ini karena tanaman tidak memperoleh pasokan oksigen, dan nutrisi. Pada saat pompa air berhenti maka air nutrisi pada gully tidak tersisa atau tergenang, sehingga dari permasalahan tersebut maka munculah sistem hidroponik DFT. Sistem hidroponik memiliki genangan nutrisi tebal pada gully, sehingga meskipun pompa air berhenti maka tanaman tidak akan layu.

Nutrisi hidroponik merupakan unsur makro dan mikro yang diperlukan tanaman untuk tumbuh dan berkembang. Unsur mikro dan makro yang terdapat pada tanah sudah terkemas dalam nutrisi AB Mix. Ada 12 unsur yang dibutuhkan tanaman yaitu unsur makro: nitrogen $(\mathrm{N})$, phosphorous $(\mathrm{P})$, potassium $(\mathrm{K})$, calcium $(\mathrm{Ca})$, magnesium $(\mathrm{Mg})$ sulphur $(\mathrm{S})$ dan unsur mikro yaitu iron $(\mathrm{Fe})$, boron $(\mathrm{B})$, manganese $(\mathrm{Mn})$ molybdenum $(\mathrm{Mo})$ copper $(\mathrm{Cu})$, zinc $(\mathrm{Zn})$. Berikut tahapan-tahapan membuat stok larutan nutrisi AB Mix untuk tanaman hidroponik (Gambar 6). Larutan nutrisi hidroponik sudah ada yang diracik dan tersedia di toko-toko pertanian, yang sering disebut $\mathrm{AB}$ Mix dengan merek ijo hydro, growmax dan lain-lain. Berikut praktik proses pembuatan stock larutan nutrisi AB Mix (Gambar 7). Bahan dan alat yang digunakan dalam proses praktik pembuatan larutan stock nutrisi diantaranya yaitu gelas 
ukur 5 Liter, ember, pengaduk, 2 drigen, 5 corong dan nutrisi padat stock A dan B. Larutan stock A dan B harus dimasukan kedalam drigen yang berbeda selanjutnya disimpan di tempat yang aman dan tidak terkena sinar matahari.

Peserta pelatihan diberikan keterampilan menyemai dengan menggunakan 2 media yaitu rockwul dan sekam bakar. Sebelum menyemai peserta diberikan pengetahuan mengenai benih yang baik yang dapat digunakan untuk semai. Benih yang baik diantaranya benih tidak kadaluarsa, daya vigor atau berkecambah memiliki presentasi yang tinggi diatas $80 \%$, murni atau tidak tercampur dengan benih lain, tidak cacat, utuh bentuknya. Ciri-ciri tersebut dapat dilihat pada kemasan benih. Benih yang disemai oleh peserta pelatihan diantaranya yaitu pakcoy, bayam, sesim, selada merah dan selada hijau.

Menyemai menggunakan rockwul terdiri dari beberapa tahapan diantaranya peserta diharuskan menyiapkan APD seperti sarung tangan plastik serta alat dan bahan yang dibutuhkan untuk menyemai, seperti benih, baki, rockwul, sekam bakar, sprayer, air, dan gelas ukur. Peserta memotong rockwul dengan ukuran 2.5 × $2.5 \mathrm{Cm}$ menggunakan gergaji besi atau gunting, rockwul yang telah dipotong kemudian dibasahi dengan air yang terdapat pada gelas ukur atau ember hingga jenuh. Selanjutnya rockwul diletakkan di atas baki dan lubangi dengan tusuk gigi, kemudian masukan benih yang disemai, tutup dengan plastik hitam dan simpan di tempat yg aman.

Media semai sekam bakar memiliki tingkat daya serap air, dan aerasi yang sangat baik dibandingkan dengan media rockwool (Rasheed et al., 2021). Berikut tahapan peserta pelatihan praktik menyemai dengan sekam bakar. Tahapan tersebut diantaranya peserta menyiapkan APD dan alat bahan, mencuci sekam bakar dengan air agar bersih, sekam bakar yang telah di cuci kemudian tebarkan ke dalam baki sebanyak $3 / 4$ baki, selanjutnya tebarkan benih yang akan disemai ke dalam baki, tutup benih yang telah ditebar dengan sekam bakar secara tipis, semprot bakar dengan spray, tutup dengan plastik hitam, dan simpan di tempat yang aman (Gambar 8).

Penutupan benih yang disemai dengan plastik hitam bertujuan agar benih benih segera pecah dan berkecambah. Pada proses tersebut tidak dibutuhkan adanya sinar matahari guna mempercepat perkecambahan. Proses penutupan benih yang disemai dalam rockwul dan sekam bakar kurang lebih sekitar 2 hari hingga 3 hari. Setelah benih berkecambah maka dilakukanlah pindah tanam dari baki ke meja semai (Gambar 9). Hasil semai pada sekam bakar diperlukan proses pemindahan ke media rockwul sebelum dipindahkan ke meja semai. 
Benih diletakan di meja semai kurang lebih 7 hari hingga 14 hari (Gambar 10). Lain halnya untuk benih kangkung dapat lebih cepat pindah tanam ke meja peremajaan dibandingkan dengan benih seperti pakcoy, selada merah, selada hijau dan sesim. Hal ini karena untuk tanaman kangkung termasuk kedalam kelompok HSS. HSS adalah proses penghitungan tanaman dimulai dari tanggal atau hari setelah semai. Kelompok sayuran yang tergolong kedalam HSS yaitu kangkung dan bayam. Pada tanaman pakcoy, selada merah, hijau dan sesim termasuk kedalam golongan HST, yaitu kelompok tanaman dengan penghitungan panen dimulai setelah hari setelah pindah tanam ke meja peremajaan. Untuk kelompok tanaman HST biasanya pada meja semai lebih lama dibandingkan tanaman kelompok HSS. Tanaman kelompok HST dilakukan pindah tanam paling minimal yaitu 10 HSS dan maksimal 14 HSS. Indikator lain tanaman yang termasuk kelompk HST dapat pindah tanam ke meja peremajaan yaitu dengan syarat tanaman tersebut sudah memiliki 4 daun. Menurut (Sharma et al., 2019) perlakuan media tanam yang sesuai akan membuat tanaman menjadi sehat sehingga dapat bertahan dari serangan hama dan penyakit.

Pengecekan nutrisi salah satu hal yang penting dalan berkebun hidroponik. Hal ini dilakukan agar kebutuhan nutrisi untuk tanaman tercukupi. Setiap tanaman membutuhkan nutrisi yang berbeda. Oleh karena itu maka disarankan setiap meja instalasi peremajaan hanya untuk satu komoditas tanaman. Pengecekan tanaman juga menjadi bagian yang harus dilakukan dalam memelihara kebun hidroponik. Setiap tanaman memiliki tingkat kesulitan yang berbeda dalam perawatan atau pemeliharaan, misalnya untuk tanaman bayam dan pakcoy sangat rentan terkena hama. Perlu adanya pemeliharan ekstra terhadap tanaman pakcoy dan bayam agar menghasilkan kualitas dan kuantitas yang baik pada saat panen.

Kriteria tanaman sayuran siap panen diantaranya, umur tanaman sudah memenuhi, sesuai dengan standar konsumen yg diinginkan, bentuk tanaman proposional, serta warna dan ukuran sesuai. Kualitas dan kuantitas panen sayuran hidroponik sangat dipengaruhi langsung oleh standar oprasional perawatan. Hasil penelitian (Wibowo \& Asriyanti, 2013) menunjukkan tanaman Pakcoy yang ditanam menggunakan sistem NFT menghasilkan panen yang lebih tinggi. Demikian juga pada tanaman selada berkualitas perlu diimbangi dengan pemberian nutrisi yang tepat

Pada akhir kegiatan pelatihan, para peserta pelatihan dihadapkan dengan ujian kompetensi. Asesor yang menguji kompetensi peserta pelatihan berjumlah 2 orang, sehingga para peserta dikelompokan menjadi 2 kelompok yang masing-masing 8 orang setiap asesor. Ujian kompetensi terdiri dari 2 metode yaitu tes tulis dan praktek. Tes tulis yang diujikan 
meliputi pemahaman terhadap materi, kepuasaan terhadap instruktur, dan pelayanan BLK Lembang. Tes praktik meliputi praktik menyemai, menggunkan APD, perawatan tanaman hidroponik, pembuatan model instalasi sistem wick, panen dan mengemas tanaman hidroponik (Gambar 13). Hasil ujian kompetensi terlampir pada sertifikat yang diberikan pada saat penutupan kegiatan pelatihan. Berakhirnya pelatihan ini disimbolisasikan dengan penyerahan sertifikat pelatihan dan pemberian worksplace (Gambar 14).

Indikator keberhasilan dari pelatihan yaitu dengan dibentuknya kelompok tani hidroponik mekar wangi. Hidroponik mekar wangi merupakan kelompok hidroponik yang terdiri dari peserta pelatihan hidroponik oleh BLK. Mekar wangi memproduksi sayuran pakcoy, bayam, kangkung, selada merah dan hijau. Setiap satu bulan sudah menghasilkan sekitar $20 \mathrm{Kg}$ sayuran. Pemasaran sayuran melalui anggota kelompok yang kemudian disalurkan melalui tempat bekerja anggota kelompok seperti intansi di sekolah, puskesmas ataupun masyarakat sekitar kecamatan Baros. Selain pemasaran hidroponik mekar wangi yang terbentuk, melalui pelatihan BLK lembang juga sudah mampu mengedukasi masyarakat sekitar seperti dengan diadakannya belajar bersama dengan anggota hidroponik mekar wangi.

\section{KESIMPULAN}

Kegiatan pelatihan hidroponik dapat memberikan pengetahuan dan mampu mengubah pola pikir masyarakat untuk memanfaatkan cara bercocok tanam dengan sistem modern yaitu hidroponik untuk memperoleh sayuran yang lebih sehat dan ramah lingkungan. Peserta pelatihan secara khususnya juga termotivasi untuk berwirausaha di bidang pertanian hidroponik dengan menjual hasil panen ke lingkungan masyarakat.

\section{UCAPAN TERIMAKASIH}

Pelaksanaan pelatihan hidroponik ini melibatkan berbagai pihak yang mendukung baik moril maupun materil, maka penulis ingin mengucapkan banyak terimakasih kepada:

1. Tuti Haryanti, S.T., M.Si selaku kepala BLK Lembang yang telah memfasilitasi dan mengadakan pelatihan di desa Panyirapan, Baros, Serang, Banten.

2. Zaki Abdul Rajak selaku instruktur BLK Lembang yang telah membimbing para peserta pelatihan kompeten di bidang hidroponik.

3. Yudi dan Tarsa selaku asesor yang telah menguji kompetensi para peserta pelatihan

4. Aparatur desa Panyirapan yang telah memberikan dukungan pada pelaksanaan pelatihan hidroponik. 
5. Para peserta pelatihan hidroponik (Hidroponik Mekar Wangi) yang selalu kompak dalam mengikuti kegiatan pelatihan

\section{DAFTAR PUSTAKA}

Aksa, M., Jamaluddin, P., \& Subariyanto. (2016). Rekayasa Media Tanam pada Sistem Penanaman Hidroponik untuk Meningkatkan Pertumbuhan Tanaman Sayuran. Jurnal Pendidikan Teknologi Pertanian, 2, 163-168.

Asmana, M. S., Abdullah, S. H., \& Putra, G. M. D. (2017). Analisis keseragaman Aspek Fertigasi pada Desain Sistem Hidroponik dengan Perlakuan Kemiringan Talang. Jurnal Ilmiah Rekayasa Pertanian Dan Biosistem, 5(1), 303-315.

Djam’an, S., \& Aan, K. (2010). Metodologi Penelitian Kualitatif. Alfabeta.

Domingues, D. S., Takahashi, H. W., Camara, C. A. P., \& Nixdorf, S. L. (2012). Automated System Developed to Control $\mathrm{pH}$ and Concentration of Nutrient Solution Evaluated in Hydroponic Lettuce Production. Computers and Electronics in Agriculture, 84, 53-61.

Frasetya, B., Taofik, A., \& Firdaus, R. K. (2018). Evaluasi Variasi Nilai Electrical Conductivity terhadap Pertumbuhan Tanaman Selada (Lactuca sativa L.) pada Sistem NFT. Jurnal Agro, 5(2), 95-102.

Harahap, L. J., Rahmadiana, V., Iman, F., Ristanto, R. H., \& Lisanti, E. (2019). Ethnoveterinary Pharmacology : Knowledge Identification of Sukarame Society, Carita, Pandeglang, Banten. Bioscience, 3(2), 187-196.

Helmi, Nursyahid, A., Setyawan, T. A., \& Hasan, A. (2016). Nutrient Film Technique ( NFT ) Hydroponic Monitoring System. JAICT (Journal of Applied Information and Communication Technologies), 1(1), 1-6.

Jerusha, S., Anand, A. V., Adarsh, J., Chandra Kumar, K. R., \& Vishnu Saravana Bharathi. (2021). Organic Hydroponic Farming Incorporated with Recycles Water. Journal of Physics: Conference Series, 1916(1).

Majid, M., Soil, M. T., Engineering, W., Khan, J. N., Shah, Q. M. A., Masoodi, K. Z., Afroza, B., \& Parvaze, S. (2020). Evaluation of Hydroponic Systems for the Cultivation of Lettuce ( Lactuca sativa L., var. Longifolia ) and Comparison with Protected SoilBased Cultivation. Agricultural Water Management, 1-13.

Maulido, R. N., Tobing, O. L., \& Adimihardja, S. A. (2016). Pengaruh Kemiringan Pipa pada Hidroponik Sistem NFT terhadap Pertumbuhan dan Produksi Selada (Lactuca sativa L.). Jurnal Agronida, 2(2), 62-68.

Palande, V., Zaheer, A., \& George, K. (2018). Fully Automated Hydroponic System for Indoor Plant Growth Fully Automated Hydroponic System for Indoor Plant Growth. Procedia Computer Science, 129, 482-488.

Pancawati, D., \& Yulianto, A. (2016). Implementasi Fuzzy Logic Controller untuk Mengatur pH Nutrisi pada Sistem Hidroponik Nutrient Film Technique (NFT). Jurnal Nasional Teknik Elektro, 5(2), 278-289.

Rasheed, J., Latif, K., Sheraz, M., \& Iqbal, A. (2021). Building indigenous smart hydroponic farm as lessons from an academic experiment-A review article. International Journal of Agricultural Technology, 17(2), 673-684.

Savvas, D. (2004). Yield and Nutrient Status in the Root Environment of Tomatoes 
(Lycopersicon esculentum) Grown on Chemically Active and Inactive Inorganic Substrates. International Symposium on Growing Media and Hydroponics, Acta Hort, 644, 377-383.

Sharma, N., Acharya, S., Kumar, K., Singh, N., \& Chaurasia, O. P. (2019). Hydroponics as an advanced technique for vegetable production: An overview Hydroponics as an advanced technique for vegetable production: An overview. Journal of Soil and Water Conservation, 17(4), 364-371.

Sugiyono. (2018). Metode Penelitian Kuantitatif, Kualitatif, R\&D. Alfabeta.

Sunardi, O., Adimihardja, S., \& Mulyaningsih, Y. (2013). Effect of Giving Gibberellin (GA3) on Vegetative Plant Growth Water Cabbage (Ipomea aquatica Forsk L.) in the Floating Raft Technique (FRT) Hydroponic System. 4(1), 33-47.

Suryaningprang, A., Suteja, J., Mulyaningrum, M., \& Herlinawati, E. (2021). Hydroponic: Empowering Local Farmer Knowhow to Gain Value Added on Agriculture Commodity. Budapest International Research and Critics Institute (BIRCI-Journal): Humanities and Social Sciences, 4(1), 787-796.

Vidianto, D. Z., Fatimah, S., \& Wasonowati, C. (2012). Penerapan Panjang Talang dan Jarak Tanam dengan Sistem Hidroponik NFT (Nutrient Film Technique) pada Tanaman Kailan (Brassica oleraceae var. alboglabra). Agrovigor, 6(2), 128-135.

Wibisono, V., \& Kristyawan, Y. (2021). An Efficient Technique for Automation of The NFT (Nutrient Film Technique) Hydroponic System Using Arduino. International Journal of Artificial Intelligence \& Robotics (IJAIR), 3(1), 44-49.

Wibowo, S., \& Asriyanti S, A. (2013). Aplikasi Hidroponik NFT pada Budidaya Pakcoy (Brassica rapa chinensis). Jurnal Penelitian Pertanian Terapan, 13(3), 159-167.

Zainudin, A., \& Abror, M. (2021). The Effect of Long - Irradiation of LED Lights on The Growth and Quality of Mustard Pakchoi Plants on Hydroponic Methods of Wick Systems. Procedia of Engineering and Life Science, 1(1), 1-9. 